\title{
Structural health monitoring for wind turbine foundations
}

Magnus Currie MEng

PhD student, EPSRC Wind Energy Systems CDT, Department of Electronic and Electrical Engineering, University of Strathclyde, Glasgow, Scotland

Mohamed Saafi MSc, PhD

Senior lecturer, Department of Civil Engineering, University of Strathclyde, Glasgow, Scotland
Christos Tachtatzis MSc, PhD, MIET, MIEEE

Research fellow, Centre for Advanced Condition Monitoring, Department of Electronic and Electrical Engineering, University of Strathclyde, Glasgow, Scotland

Francis Quail MPhil, PhD, CEng, FIMECHE, FIEI, FCMI

Department of Mechanical Engineering, University of Strathclyde, Glasgow, Scotland

The construction of onshore wind turbines has been increasing rapidly as the UK attempts to meet its renewable energy targets. As the UK's future energy depends increasingly on wind farms, safety and security are critical to the success of this renewable energy source. Structural integrity of the tower and its components is a critical element of this security of supply. With the stochastic nature of the load regime, a bespoke structural health monitoring system is required to monitor the integrity of the concrete foundations supporting the tower. This paper presents an assessment of 'embedded can'-style foundation failure modes in large onshore wind turbines and proposes a novel condition-based monitoring solution to aid in early warning of failure.

\section{Introduction}

Large-scale development of onshore wind turbines as part of a strategy to meet UK government targets has been a result of the government's obligations to reach EU carbon dioxide reduction targets. Increasing the percentage of renewable energy in the electricity mix, displacing older, fossil fuelled, thermal generation will result in wind energy becoming an important component. The UK has a target to produce $15 \%$ of its energy needs through renewable methods by the year 2020 (DECC, 2011). In order to meet this ambitious target, numerous wind farms have been constructed recently and others are under construction or in planning phases. Ensuring the reliability of wind turbine structures allows safe operation and maximum availability.

Wind turbines operate under challenging loading regimes (Burton et al., 2001) the effects of which could diminish their structural integrity leading to significant remediation costs and the potential for damaging publicity. Over time, the onshore turbine structure will become less efficient and less effective when compared with a new one. This can be caused by numerous factors including environmental exposure, fatigue of blades, tower and concrete foundations, soil settlement, poor construction and poor maintenance. Protecting assets and maximising power production are challenges and priorities for wind turbine operators. Structural health monitoring (SHM) provides the means to track the structural condition of turbines throughout their 20-25-year life cycle (Ciang et al., 2008). Health and condition monitoring systems are often used on components such as the gearbox but are used less frequently to monitor the state of structural components (Hamilton and
Quail, 2011). There are three main areas in which SHM can be applied to an onshore wind turbine: the rotor (including the blades), the tower and the foundations. Each structural component presents different structural problems, failure modes and failure rates.

This paper considers some technical challenges including structural behaviour/failure modes of onshore wind turbines and the effect on wind turbine foundations. Current health monitoring technologies with potential applications to onshore wind turbines are considered, and a novel health monitoring strategy for the wind turbine's foundations with continuous proactive capability is presented. The paper also presents some key research themes to develop a robust SHM technology. Structural failure rates and an analysis of foundation failure modes are presented. The outcome of a field visit to a wind farm site exhibiting signs of failure is then covered. Finally, a novel SHM system is proposed to monitor the level of failure in the foundations continuously.

\section{Practical relevance and potential applications}

The objective of this paper is to shed some light on the behaviour of gravity concrete foundations used in onshore turbines, and identify the most common structural damage encountered in these foundations. The paper also presents a new remote monitoring system for the foundations. The monitoring system consists of remotely measuring the displacement of the can connection embedded in the concrete foundations due to the internal damage and defects. Based on this research a number of structural damages are identified and presented in the tower-foundation 
connection system. In addition, three low-cost sensors were identified for the proposed health monitoring system.

The structural damages highlighted in this paper will help civil engineers understand better the behaviour of wind turbine foundations under dynamic loading conditions, which in return will help them improve the design methods and develop countermeasure techniques. The proposed monitoring will also benefit the civil engineering community involved in the design, construction and management of onshore wind farms. The monitoring system will reduce structural failures associated with excessive displacement of the can connection by providing an early warning.

\section{Structural damage in onshore wind turbines}

Figure 1 shows a typical onshore wind turbine, with blades, tower and gravity concrete foundations. The main types of foundation-tower interface used for large onshore turbines include the use of an embedded steel can or a ring of bolts. This paper will focus on the embedded can style, which has been showing the most serious signs of failure.

Current research is focused on structural damage of blades and towers; specific information on the structural behaviour of wind turbine foundations, however, is very limited. In particular there is a lack of in-depth reporting of failures. Tavner et al. (2006) provide a useful guide to the levels of component structural failure within turbines in several countries. The work shows the blade failure rate including pitch mechanism of between 0.2 and 1.0 per turbine per year, although the average is closer to 0.2 . The actual blade failure rate (not including the pitch mechanism) is much lower, reaching 0.025 failures per turbine per year as calculated in Echavarria et al. (2008). A survey effort of more than 1500 offshore wind turbines conducted by the European Scientific Measurement and Evaluation Program (WMEP) showed that the blade failure rate is approximately 0.11 per turbine per year, whereas the failure rate of support
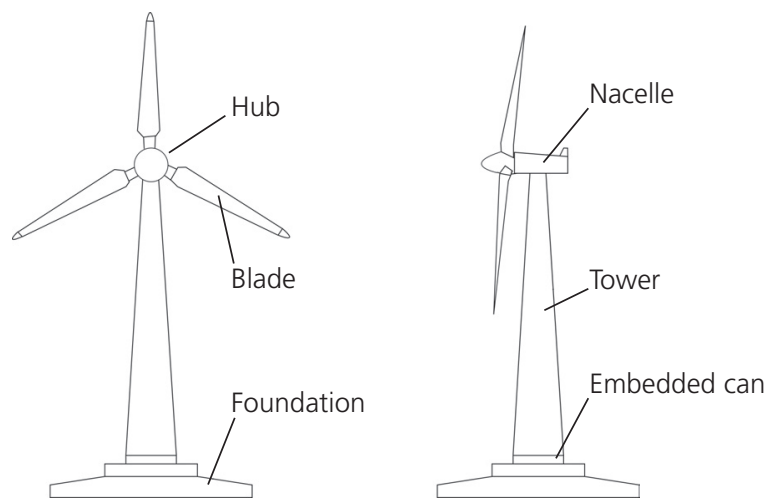

Figure 1. Components of large-scale wind turbine and housing is about $0 \cdot 1$ failures per turbine per year (Faulstich et al., 2011). The same survey shows that the rate of failure of the nacelle is 0.003 failures per year per turbine and the tower failure is approximately 0.001 . Based on the literature review, it was found that the average turbine is extremely unlikely to suffer failure of the tower or the nacelle. However, the chance that one of the blades could fail during its life cycle is approximately $50 \%$. The fragility of the blades and the risk of failure is demonstrated by the large amount of research work in that area compared to articles concerning the turbine tower and foundations.

\section{Damage mechanisms and failure modes of wind turbine foundations}

It is unknown how reliable wind turbine foundations are as there is a lack of published data available. While a complete collapse of a turbine is very rare, non-catastrophic localised failure of the reinforced concrete elements of foundations appears to be more frequent based on interviews carried out with wind farm operator staff. Recent studies showed that the structural failures in the tower and foundations account for only a very small percentage of the total number of failures $1.5 \%$ of failures and $1.2 \%$ of downtime (Ribrant and Bertling, 2007). Wind turbine foundations are normally subjected to large cyclic moments and forces and, if designed incorrectly, this could produce structural damage in the foundations and jeopardise the stability of the wind turbine. Problems in the foundations can manifest themselves in a number of ways including deterioration of the underlying fill and ground below the foundations or in the degradation of the reinforced concrete pedestal and base.

Long-term cyclic loading causes the foundation-soil interface to degrade, resulting in a reduced rotational stiffness, which in return decreases the bearing capacity of the soil. In this case, gravity foundations exhibit large differential movement and can tilt under a high lateral wind load. A significant number of foundation failures and tower collapses have occurred during periods of extreme weather and high wind speeds.

The embedded can foundation is illustrated in Figure 2. The steel can is embedded within the concrete foundations then the tower section is attached to the top flange of the can.

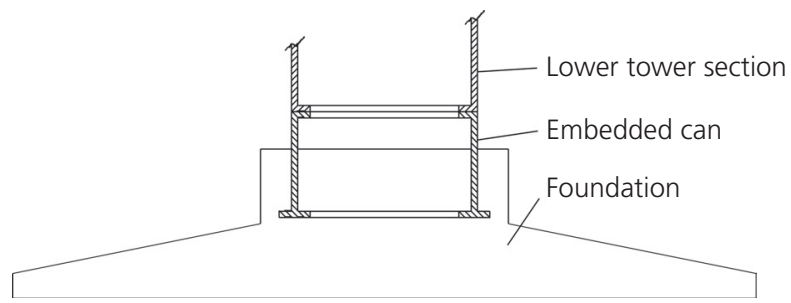

Figure 2. Cross-section of an embedded can foundation (not to scale) 


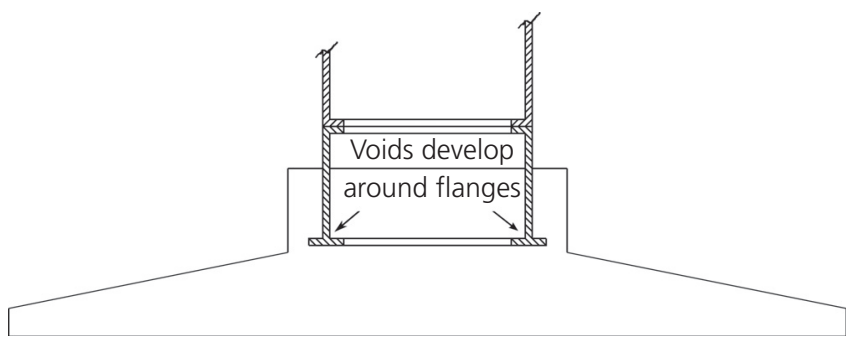

Figure 3. Area where voids develop around embedded can bottom flange

Figure 3 shows the area where voids can develop in concrete foundations for embedded can-type connections when the turbine is subjected to eccentric and cyclic loading. Erosion around the flange can occur as the embedded can moves against the concrete, with sediments being removed through hydraulic action.

The presence of voids around the embedded can allows the whole tower to move significantly in the vertical direction as well as to a smaller extent in the horizontal direction. There has been little published work relating to this type of displacement, but movements of approximately $5 \mathrm{~mm}$ were noted during a site visit, with reports of movement up to $20 \mathrm{~mm}$ on other turbines at the same site.

\section{Embedded can failure modes}

The failure of the embedded can is complex and has several different possible failure modes, which may act as one or together over time to accelerate the failure of the foundations. The exact cause of the movement has not yet been pinpointed by the operator. The steel can has a diameter of $4 \mathrm{~m}$. The foundation has a total diameter of $15 \mathrm{~m}$ at its base and sits on solid rock. During construction, the steel can is sited and concrete is then poured around to complete the upper part of the foundations. Failure of each foundation is not identical and some may fail at varying rates. During a site visit, turbines were inspected that were showing various levels of movement. The general order of events is listed below.

(a) Small movements of the tower are possible due to the low level of friction between the painted can and the concrete. As the tower moves during operation the green plasticised waterproof membrane eventually cracks. Cracking occurs principally around the area between the pedestal and the penetrating steel can. This is shown in Figure 4. There was no evidence that cracking was only occurring in a uniform manner. Some turbines had only small single cracks, whereas others had cracks extending to approximately $2 \mathrm{~m}$ around the circumference of the foundation-tower connection.

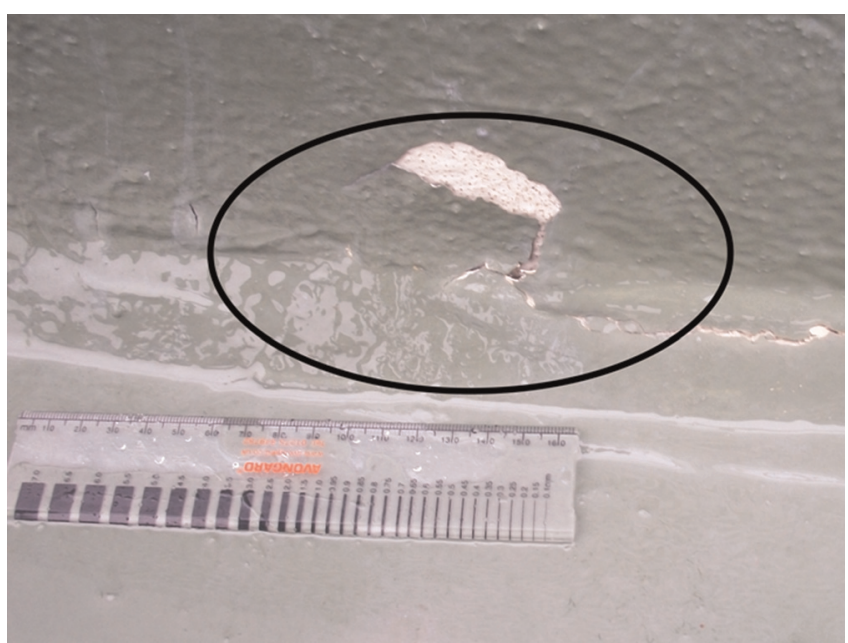

Figure 4. Cracking in the waterproof membrane between tower and foundation

(b) With the waterproof membrane cracked, water is able to penetrate the foundations, migrating down the gap between the steel can and the concrete. Water migrates between pores within the concrete as well as finding pathways along construction joints. However, with the waterproofing breached, much greater volumes of water can penetrate the entire way around the foundations even if there is only cracking at one location. During the site visit it was noted that the water ingress was compounded by ponding on several pedestals and also the constant flow of water running down from the tower during precipitation.

(c) The presence of water at the base of the embedded can coupled with the continual movement of the tower creates an environment in which erosion begins to take place. The force of the tower movement results in concrete being eroded. The eroded concrete particles mix with the water to create a paste.

(d) Evidence of internal foundation erosion is visible at the surface in the form of cementitious deposits being pumped through the cracks at the top of the foundation pedestal (see Figure 5). Larger particles that become dislodged such as aggregate are broken up inside the foundations.

(e) Voids are created where material is eroded. The presence of voids has been confirmed through the use of remote cameras inserted into the foundations through small boreholes. Video evidence, on this specific foundation, shows the steel can moving in the vertical direction and water being transported around it.

( $f$ ) As the depth and width of the void increases the steel can is able to move more in the vertical direction as well as to a smaller extent in the horizontal direction. Erosion is possible both beneath and on the upper side of the flanges. 


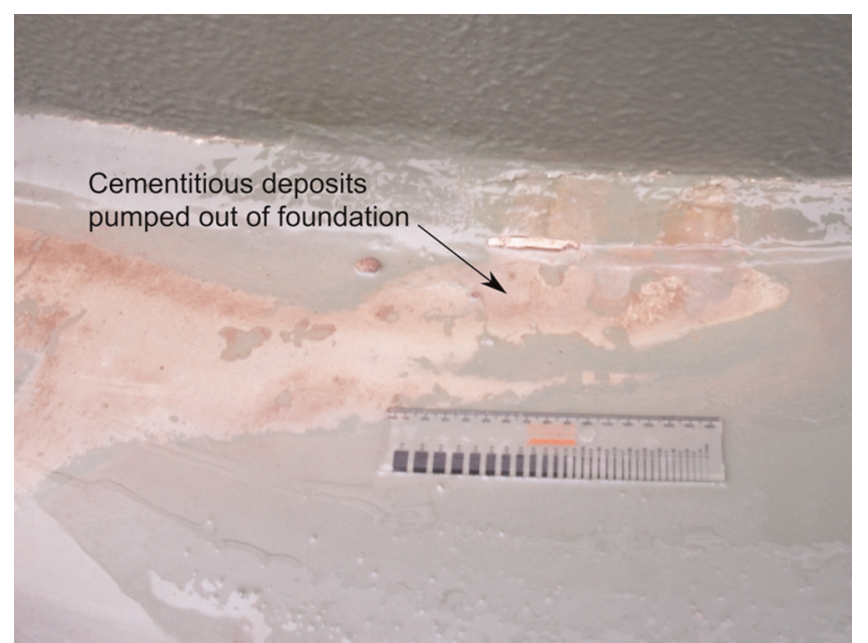

Figure 5. Cementitious deposits flowing from the foundations through cracks in the waterproof membrane

(g) As the steel can movement increases, increased erosion and the magnitude of movement occurs. The amount of material being released from the foundations at the surface is different in each individual case and while it can be used to suggest a problem it is not enough to determine the scale or nature of the failure mode.

(h) Eventually, the movement reaches a level where remedial action is required. At this particular wind farm it was decided to pump grout into the void in an effort to stabilise the steel can. It is not known for how long this solution will be effective. The turbines, which had undergone remedial work, were not showing any signs of movement after 12 months.

The pattern of failure has been noted in a number of turbines on several sites, with some turbines showing failure early in their operational life and others taking a longer time to develop symptoms. The failures witnessed on site represent a specific wind farm.

\section{Foundation monitoring}

Current monitoring for the wind turbines in the study involves a technician visiting each turbine on a regular basis to record visible movement using a surveying theodolite. Inspections are increased when there is a significant change in the magnitude of vertical movement. This method of inspection is time consuming and costly as well as being unavailable for extended periods during winter conditions. The technician on site calls for the operating station to request the turbine to be temporarily paused. The greatest movement can be seen during shutdown when it is operating at or above its rated wind speed. While this method has been used successfully there are some key drawbacks, which make it ineffective and inefficient including site access difficulties during winter, the lack of ongoing monitoring and the use of staff resources.

A novel sensing solution to monitor the state of large-scale multi-megawatt wind turbine foundations is proposed in this paper. The system has been designed for 'embedded can'-style foundations. The only data currently gathered on the tower movement is based on accelerometer readings from the nacelle. These data do not give specific details on the foundations. It is unknown how widespread the problems are due a lack of published data relating to wind turbine foundations. The authors are proposing an inexpensive monitoring solution that actively monitors the structural integrity of the turbine and reports its status to a remote technical centre (RTC) or head office. Inspection of the displacement data and trending can enable technical personnel to improve the understanding of failures and allow the development of appropriate techniques to resolve them.

\section{Design requirements}

The design requirements for the SHM system to diagnose tower displacement for can-style foundations are as follows:

(a) Accurate sensing with a resolution of $0.1 \mathrm{~mm}$.

(b) Robust under conditions inside the tower; this includes the presence of oils, hydraulic fluids, moisture and varying temperatures.

(c) Measurement frequency of $10 \mathrm{~Hz}$ to enable suitable detection of tower displacement.

(d) Multiple displacement sensors will be placed around the tower to enable complete profiling of the tower displacement ensuring measurements are not dependent on wind direction.

(e) Data processing and aggregation of the individual sensors allowing the development of a simple traffic light notification system to enable personnel easily to interpret the status of each foundation.

$(f)$ The data collected and processed for each foundation will be categorised for the asset operator. An example classification is indicated in Table 1 . The categories have been defined by the asset operator and relate to the degree of the movement. It should be noted that vertical displacement up to $18 \mathrm{~mm}$ has been recorded by engineers. Data from other sites have been difficult to

\begin{tabular}{lll}
\hline Displacement: $\mathrm{mm}$ & Warning light & Action \\
\hline $1-2$ & Green & Least concern \\
$3-5$ & Amber & Increased inspection \\
$>5$ & Red & Inspection/remediation
\end{tabular}

Table 1. Foundation displacement warning system 
acquire due to the commercial sensitivities involved, although it is thought that movements up to $40 \mathrm{~mm}$ are possible without total foundation failure and wind turbine overturning. The initial 1-2 $\mathrm{mm}$ accounts for the elastic stretching of the tower under loading.

\section{Sensing solutions}

Numerous types of displacement sensors are available. However, many are not suitable for the climate within the turbine, are too costly or would pose difficulties during installation. The most suitable for the application on the foundations are infrared, linear variable differential transformers (LVDTs) and Halleffect sensors. Experimental work is in progress to identify the most suitable device for health monitoring of wind turbine foundations based on the design requirements described above. It is envisaged that the initial deployment will consist of all these sensors to identify the most suitable for the wind turbine environment (such as oil, electromagnetic interference, mechanical movement and vibration). The principle of the three devices is described below and a health monitoring architecture for a wind turbine concrete foundation is proposed. The measurement for each device is between the stationary concrete floor and the tower flange, which is moving vertically.

\subsection{Infrared sensor}

Off-the-shelf infrared sensors have an integrated positionsensitive detector and infrared emitting diode (http:// www.sharpsme.com/webfm_send/1476). The operating layout of the sensor is illustrated in Figure 6. All other sensors considered measure this same distance.

The sensor functions by sending an infrared signal towards a reflective surface. The signal is then reflected back to the sensor where it is picked up by the receiver. As the displacement between the sensor and the target reflector increases, the voltage output of the device reduces. The components for the sensor are low cost and low power. If they are installed in the turbine they will need to be protected to prevent the sensor and receiver becoming covered by dust and residues. This can easily be achieved using a flexible sheath between the sensor and reflector. High reflectance material, such as aluminium tape, can easily be applied to the target surface in order to ensure a

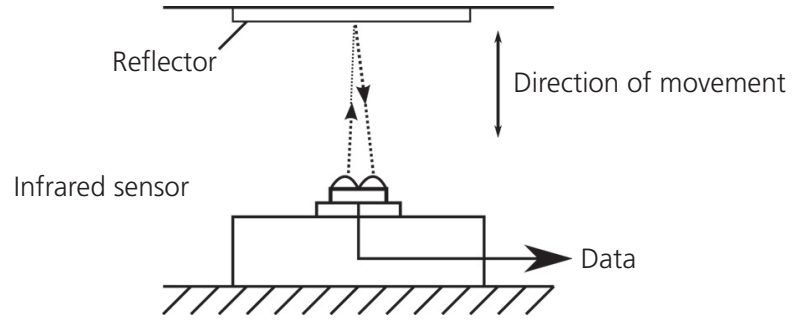

Figure 6. Sensing displacement between the concrete foundation (bottom) and the flange of the embedded can (top) simple installation. The lack of moving parts also reduces the need for ongoing maintenance.

\subsection{LVDT sensor}

LVDTs have been used in a number of linear displacement structural health applications. During operation the electrical output of the sensor changes relative to displacement. There is a wide range of sensors with varying stroke lengths and resolutions. In the case of the foundations a small stroke length of $50 \mathrm{~mm}$ would be sufficient - the middle range being the most accurate, with accuracy tailing off at the beginning and end of the stroke. LVDT sensors come with various protections from the elements, making them a robust option. However, they are a more expensive sensing solution compared to the noncontact infrared and Hall-effect sensors, with the cost being significant if an array is proved to be the best option.

\subsection{Hall-effect sensor}

Hall-effect sensors utilise the varying magnetic field around a permanent magnet. With a greater distance from the magnet the level of magnetic field reduces. The current in the sensor changes relative to the level of magnetic field. The sensor is suitable because it has no moving parts and no optical devices, which could otherwise become coated with residues found in the turbine tower. The sensors considered are shown in Table 2 with advantages and disadvantages noted.

\section{Condition monitoring}

Data gathered from the chosen sensor system will be analysed and displayed in a manner suitable for the asset owner. A Bayesian inference program (BIP) will be used to determine the state of the foundation condition. The initial objective of the system is to provide an early warning indication of the tower movement and not to identify the particular type of foundation failure. The early warning system provides an indication that further investigation may be necessary.

\subsection{LabVIEW BIP}

To analyse data from each sensor, a BIP will be used. Initially, probability density functions are created for each foundation condition (green, amber and red). Once the sensor is active, data are fed into the BIP where it determines the state condition of the foundations. The output is a simple traffic light system, which is easy and quick to interpret by the technician staff monitoring the foundations. It is envisaged that additional inputs such as wind speed will be added. It is also quick and easy to change the levels of each of the three conditions, for example to change the critical limit from $5 \mathrm{~mm}$ displacement to $6 \mathrm{~mm}$.

\subsection{Communication system architecture}

The proposed communications system architecture is shown in Figure 7. Multiple sensors (S) will be deployed on the turbine 


\begin{tabular}{|c|c|c|c|c|}
\hline Technique & Measurement principle & Advantage & Disadvantage & Relative cost \\
\hline Infrared & $\begin{array}{l}\text { Time of flight of } \\
\text { infrared signal }\end{array}$ & Lowest cost option & $\begin{array}{l}\text { High risk of target or sensor } \\
\text { being covered by residues }\end{array}$ & Low $<$ f50 \\
\hline LVDT & Voltage differential & $\begin{array}{l}\text { High accuracy and easy installation; } \\
\text { protected from elements }\end{array}$ & Higher cost & $\begin{array}{l}\text { High } \\
\text { f200-400 }\end{array}$ \\
\hline $\begin{array}{l}\text { String } \\
\text { potentiometer }\end{array}$ & $\begin{array}{l}\text { Electrically variable with } \\
\text { displacement }\end{array}$ & Simple installation & $\begin{array}{l}\text { Moving parts at risk of getting } \\
\text { clogged }\end{array}$ & $\begin{array}{l}\text { High } \\
\text { f200-400 }\end{array}$ \\
\hline Hall effect & $\begin{array}{l}\text { Electrically variable with } \\
\text { magnetic signal }\end{array}$ & $\begin{array}{l}\text { Simple to install and results not } \\
\text { compromised by dirt }\end{array}$ & $\begin{array}{l}\text { Electromagnetic radiation from } \\
\text { the high-voltage cable may } \\
\text { heavily interfere }\end{array}$ & $\begin{array}{l}\text { Medium } \\
\text { f50-200 }\end{array}$ \\
\hline
\end{tabular}

Table 2. Sensor selection ( $f 1=€ 1 \cdot 16$, Feb., 2013)

foundations, sampling continuously for displacement and reporting the measurements to a data aggregator device (A) located in the turbine. The communications between the sensors and the data aggregation device could be either wired or wireless.

In order to reduce the installation cost and ease deployment a wireless solution based on the widely used and mature communications standard IEEE 802.15.4 (IEEE, 2011) will be adopted. Using this technology, devices can operate for more than 3 years with two AAA batteries reporting every $10 \mathrm{~s}$ (Casilari et al., 2010), making it ideal for SHM applications.

Aggregator devices are used to combine measurements from the displacement sensors in order to create a displacement profile of the tower as a whole. Also correlation of displacement readings and measurement verification can be achieved at this level. For example, ambiguous readings from sensors placed at the same proximity can be identified and either excluded from processing (i.e. when the sensor readings disagree) or using correlation

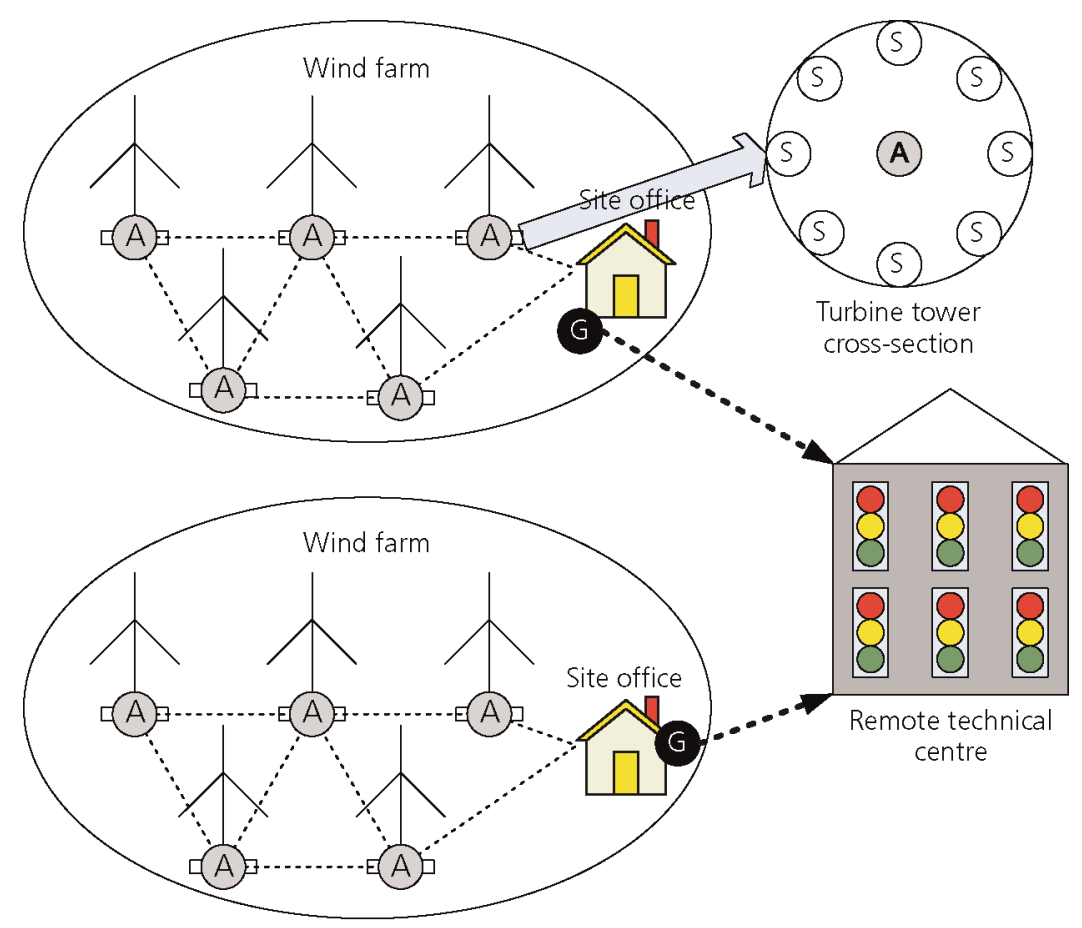

Figure 7. Sensor communication architecture. A: aggregator device, G: gateway device, S: sensor 
techniques with reciprocal sensor locations to salvage the reading.

After initial processing, the aggregator devices transmit the combined measurements over the existing supervisory control and data acquisition infrastructure to the RTC for further processing and classification using a traffic light system (green, amber, red). The classification and processing will be performed by BIP and will allow the human-machine interface to display the status of each individual turbine in an easy-tounderstand format. For wind farms where supervisory control and data acquisition infrastructure is restricted or not available due to warranty issues, an autonomous communications solution will be provided. In this scenario, aggregator devices will transmit aggregate measurements to a gateway device (G), which is physically located in the site office. The gateway device will have two communication interfaces.

(a) A wireless interface to communicate with the aggregators This interface will be based on IEEE 802.15.4 and enlist the aid of aggregators to route measurements from remote locations of the wind farm (i.e. turbines that do not have a direct link to the site office due to limited range).

(b) An internet-capable interface (i.e. GPRS/HSDPA WiMAX, ethernet, ADSL, cable) for communications with the RTC.

In order to minimise the communications overhead over the internet link, the BIP will perform the classification on the gateway device and while the turbine status is green only update notifications will be sent back to the RTC for humanmachine interface purposes. When the turbine status changes to amber and red, then the gateway will stream measurements back to the RTC along with the normal notifications for further processing, inspection and analysis from technical staff. If a wind farm consists of a large number of turbines, multiple gateway devices may be deployed, increasing data communication bandwidth, reliability and availability.

In the proposed monitoring system, the displacement data are trended with real-time wind speeds from anemometer point measurements, enabling the operator to gain a clear indication of the relationship between movement and damage. It is expected that displacements are the highest during start-up and shut-down events and periods of extreme weather conditions. Further work must be undertaken to test and commission the solution and to prove it is robust for this application.

\section{Field implementation}

Work is in progress to implement the proposed health monitoring to an onshore wind turbine foundation of a $2.0 \mathrm{MW}$ device constructed in the past 10 years, and it is likely that the foundation is vulnerable to structural damage. The field implementation will evaluate the performance of the developed monitoring system and quantify the reliability of the sensor under environmental and dynamic loading conditions.

\section{Conclusions}

Embedded can wind turbine foundations have been displaying signs of failure in the form of vertical displacement. Several inexpensive sensors have been suggested as being suitable for integration in a simple SHM system to monitor real-time displacements continuously in embedded can-style wind turbine foundations. A remote monitoring based on wireless sensor networks is presented. In this monitoring, the data acquisition and processing architecture allows the asset operator to reduce inspection costs while providing greater levels of realtime information. On identifying the most suitable device for displacement measurement, the proposed health monitoring will be implemented into damage-vulnerable onshore foundations to evaluate the performance of the monitoring systems.

\section{Acknowledgements}

The authors would like to acknowledge the financial support from the EPSRC Wind Energy Systems Centre for doctoral training at the University of Strathclyde. The authors would also like to thank the Centre for Advanced Condition Monitoring for providing technical support.

\section{REFERENCES}

Burton T, Sharpe S, Jenkins N and Bossanyi E (2001) Wind Energy Handbook. Wiley, Chichester, UK, pp. 211-219.

Casilari E, Campos G and Cano JM (2010) Characterization of battery consumption in 802.15.4/ZigBee sensor motes. Proceedings 2010 IEEE International Symposium on Industrial Electronics, Bari, Italy. Institute of Electrical and Electronics Engineers, New York, NY, USA, pp. 3471-3476.

Ciang CC, Lee JR and Bang HJ (2008) Structural health monitoring for a wind turbine system: a review of damage detection methods. Measurement Science \& Technology 19(12): 1-20.

DECC (Department of Energy and Climate Change) (2011) UK Renewable Energy Roadmap. DECC, London, UK.

Echavarria E, Hahn B, Bussel GJWv and Tomiyama T (2008) Reliability of wind turbine technology through time. Journal of Solar Energy Engineering 130(3): 031005-031008.

Faulstich S, Hahn B and Tavner PJ (2011) Wind turbine downtime and its importance for offshore deployment. Wind Energy 14(3): 327-337.

Hamilton A and Quail F (2011) Detailed state of the art review for the different online/inline oil analysis techniques in context of wind turbine gearboxes. Journal of Tribology 133(4): 044001-044018. 
Energy

Volume 166 Issue EN4
Structural health monitoring for wind

turbine foundations

Currie, Saafi, Tachtatzis and Quail
IEEE (Institute of Electrical and Electronic Engineers) (2011) IEEE Std 802.15.4-2011 (revision of IEEE Std 802.15.4-2006): IEEE standard for local and metropolitan area networks - part 15.4: low-rate wireless personal area networks. IEEE, New York, NY, USA, pp. 1-314.

Ribrant J and Bertling LM (2007) Survey of failures in wind power systems with focus on Swedish wind power plants during 1997-2005. IEEE Transactions on Energy Conversion 22(1): 167-173.
Tavner P, Van Bussel GJW and Spinato F (2006) Machine and converter reliabilities in wind turbines in power electronics, machines and drives. In Proceeding of the $3 \mathrm{rd}$ IET International Conference on Power Electronics Machines and Drives (PEMD) 2006, Dublin, Ireland. Institution of Engineering and Technology, London, UK, pp. 127-130.

\section{WHAT DO YOU THINK?}

To discuss this paper, please email up to 500 words to the editor at journals@ice.org.uk. Your contribution will be forwarded to the author(s) for a reply and, if considered appropriate by the editorial panel, will be published as a discussion in a future issue of the journal.

Proceedings journals rely entirely on contributions sent in by civil engineering professionals, academics and students. Papers should be 2000-5000 words long (briefing papers should be 1000-2000 words long), with adequate illustrations and references. You can submit your paper online via www.icevirtuallibrary.com/content/journals, where you will also find detailed author guidelines. 